\title{
Comparison of outcomes following isolated repair of tricuspid versus bicuspid aortic valves
}

\author{
Anatol Prinzing ${ }_{1,2,3}^{1,2}$, Johannes Boehm $^{1,2}$, Magdalena Erlebach ${ }^{1,2}$, Konstantinos Sideris $^{1,2}$, Ruediger Lange ${ }^{1,2,3}$, \\ Markus Krane $e^{1,2,3}$
}

${ }^{1}$ Department of Cardiovascular Surgery, German Heart Center Munich, Technische Universität München, Munich, Germany; ${ }^{2}$ Insure (Institute for Translational Cardiac Surgery), Department of Cardiovascular Surgery, German Heart Center Munich, Technische Universität München, Munich, Germany; ${ }^{3}$ DZHK (German Center for Cardiovascular Research), Partner Site Munich Heart Alliance, Munich, Germany

Contributions: (I) Conception and design: A Prinzing, M Krane, R Lange; (II) Administrative support: A Prinzing, M Krane, R Lange; (III) Provision of study materials: A Prinzing, K Sideris; (IV) Collection and assembly of data: A Prinzing, K Sideris; (V) Data analysis and interpretation: A Prinzing, M Krane, J Boehm, M Erlebach; (VI) Manuscript writing: All authors; (VII) Final approval of manuscript: All authors.

Correspondence to: Anatol Prinzing, MD. Department of Cardiovascular Surgery, German Heart Center Munich, Lazarettstr. 36,80636 Munich, Germany. Email: prinzing@dhm.mhn.de.

Background: Aortic valve repair (AV-repair) is an alternative treatment option for patients with aortic regurgitation (AR), but durability is still reason for concern, especially for bicuspid aortic valves (BAV). We retrospectively evaluated mid-term results after AV-repair in patients with BAV or tricuspid aortic valves (TAV), including reoperation rates, recurrence of regurgitation, and survival.

Methods: Patients undergoing AV-repair between November 2004 and March 2016 without procedures involving the aortic root were included. Echocardiographic examinations were performed before and after the operation and at follow-up. Repair techniques were recorded and evaluated.

Results: Of 150 patients, 89 (59.3\%) had TAV and 61 (40.7\%) BAV. AR $\geq$ moderate was found in 66 patients with TAV (74.2\%) and 49 with BAV (80.3\%). At discharge, 74 TAV-patients had $\leq$ mild AR (84.4\%), 11 (12.4\%) moderate. 57 patients (93.4\%) with BAV had $\leq$ mild AR, 1 (1.6\%) moderate and 2 (3.3\%) severe. Mean follow-up was $4.4 \pm 2.7$ years with $\leq$ mild AR in 56 TAV patients $(73.7 \%)$ and moderate in $18(20.2 \%)$. In patients with BAV, $43(76.8 \%)$ had $\leq$ mild AR and $4(6.6 \%)$ moderate. Survival in patients with TAV was significantly decreased compared to $\mathrm{BAV}(\mathrm{P}=0.033)$, but reoperation-rates did not differ significantly $(\mathrm{P}=0.651)$.

Conclusions: AV-repair is a safe and feasible option in patients with AR and can achieve similar results in patients with TAV and BAV. The complexity of the repair technique predicts repair failure.

Keywords: Aortic valve repair (AV-repair); tricuspid aortic valve (TAV); bicuspid aortic valve (BAV); aortic valve regurgitation

Submitted Dec 29, 2019. Accepted for publication May 11, 2020.

doi: $10.21037 /$ jtd-19-4193

View this article at: http://dx.doi.org/10.21037/jtd-19-4193

\section{Introduction}

Historically, prosthetic valve replacement has been the primary treatment for patients with severe aortic regurgitation (AR). Aortic valve repair (AV-repair) has become an alternative therapeutic option for these patients, yielding satisfactory mid- and long-term results. Price and colleagues reported a 10 -year survival rate after AV- repair of $73 \% \pm 5 \%$ with freedom from significant AR of $84.9 \% \pm 2.7 \%$ and freedom from reoperation of $86 \% \pm 3 \%$ (1). The main advantages of $\mathrm{AV}$-repair are preservation of the native valve with subsequent avoidance of anticoagulation and a lower risk of endocarditis compared to that associated with prosthetic valve replacement (2). However, durability of the repair is an ongoing reason for concern, especially in patients 
with bicuspid aortic valves (BAV) (3-7). Additionally, most of the available data on $\mathrm{AV}$ - repair include procedures involving the aortic root such as remodeling or reimplantation techniques. The aim of this study was to evaluate mid-term results after AV-repair without root procedures in patients with either BAV or tricuspid aortic valves (TAV), including reoperation rates, recurrence of regurgitation, and survival. We present the following article in accordance with the STROBE reporting checklist (available at http://dx.doi. org/10.21037/jtd-19-4193).

\section{Methods}

The local ethic committee of the medical faculty at the Technical University of Munich approved the study (524/19S). Patients undergoing AV-repair without aortic root involvement between November 2004 and March 2016 were identified retrospectively in our institutional database. Based on the intraoperative findings, patients were divided into TAV and BAV groups. Pre- and postoperative transthoracic echocardiography (TTE) assessed the severity of AR (graded: none, mild, moderate, severe), peak and mean pressure gradients across the aortic valve, left-ventricular ejection fraction (LVEF), and left-ventricular end-systolic (LVESD) and end-diastolic diameters (LVEDD) (8). Every patient underwent intraoperative trans-esophageal echocardiography before and after cardiopulmonary bypass $(\mathrm{CPB})$. The policy in our institution is to preserve a native valve whenever possible, regardless of the patients' age. If patients present with regurgitant aortic valves, intraoperative analysis of the valve is performed and, based on these findings, the decision to AV-repair or prosthetic valve replacement is made. After AV-repair, we only accept intraoperatively $\mathrm{AR} \leq$ mild, measured by trans-esophageal echocardiography.

In patients undergoing $\mathrm{AV}$-repair, multiple techniques are applied, and in many cases, more than one technique is used to treat different pathologies. For thorough analysis, we further classified the different reconstructive techniques according to the level of complexity: we considered patch implantation as the technically most demanding procedure, followed by triangular resection, cusp plication, and isolated subcommissural annuloplasty (SCA). If more than one reconstructive technique was applied, patients were allocated according to the most complex technique.

After discharge, echocardiographic data were obtained from the referring cardiologists. Statistical analysis was done using IBM SPSS Version 23 (IBM, Armonk, NY,
USA). Continuous variables are reported as mean \pm standard deviation. For all categorical variables, absolute and relative frequencies are provided. Survival and freedom from reoperation are presented as Kaplan-Meier curves and statistical significance was calculated with the log-rank test. Normal distribution was tested using the KolmogorovSmirnov-test. T-tests were performed for paired and unpaired samples. $\mathrm{P}$ values $<0.05$ were considered as significant.

\section{Results}

Between November 2004 and March 2016, 150 patients underwent surgical reconstruction of the aortic valve. A TAV was found in 89 patients $(59.3 \%)$ and a BAV in 61 patients $(40.7 \%)$. Demographic data and comorbidities are provided in Table 1 . The BAVs were classified intraoperatively according to the Sievers classification (Sievers type 1 (59; 96.7\%), Sievers type 0 (2;3.3\%)] (9). Of the patients with Sievers Type 1 BAV, 55 (93.2\%) had a fused left-right coronary cusp and $4(6.8 \%)$ had a fused right non-coronary cusp. Preoperative TTE showed a similar percentage of more than moderate AR in TAV (66 patients, $74.2 \%$ ) and $\mathrm{BAV}$ (49 patients, $80.3 \%$ ). In all patients with mild AR in preoperative TTE, intraoperative TEE showed moderate AR, which prompted AV-repair. Detailed echocardiographic data are shown in Table 2.

The most commonly used surgical techniques were subcommissural annuloplasty (SCA) (132 cases; 88\%), cusp plication (86 cases; $57.3 \%$ ), triangular resection (43 cases; $28.7 \%$ ), and patch implantation (17 cases; $11.3 \%$ ). Mean $\mathrm{CPB}(\mathrm{P}=0.062)$ and aortic cross-clamp time $(\mathrm{P}=0.395) \mathrm{did}$ not differ significantly between patients with TAV and BAV (Table 1). Concomitant procedures were performed in $66(74.2 \%)$ of the patients with TAV and $37(60.7 \%)$ of the patients with BAV (Table 1). Prior to discharge, TTE in patients with TAV revealed no or mild AR in 74 (84.4\%) and moderate AR in 11 (12.4\%). In patients with BAV, 38 (62.3\%) had no AR, and 19 (31.1\%) had only mild AR; one patient (1.6\%) had moderate AR and $2(3.3 \%)$ had severe AR.

The overall mean follow-up time was $4.4 \pm 2.7$ years and was complete in $100 \%$ for survival and reoperation rates and in $91.6 \%$ for echocardiographic data. For patients with $\mathrm{TAV}$, echocardiographic data revealed no or mild AR in 56 patients (73.7\%) and moderate AR in 18 (20.2\%) at followup. For patients with BAV, echocardiography revealed no or mild AR in 43 patients (76.8\%) and moderate AR in 4 (6.6\%) 
Table 1 Baseline demographics and concomitant procedures

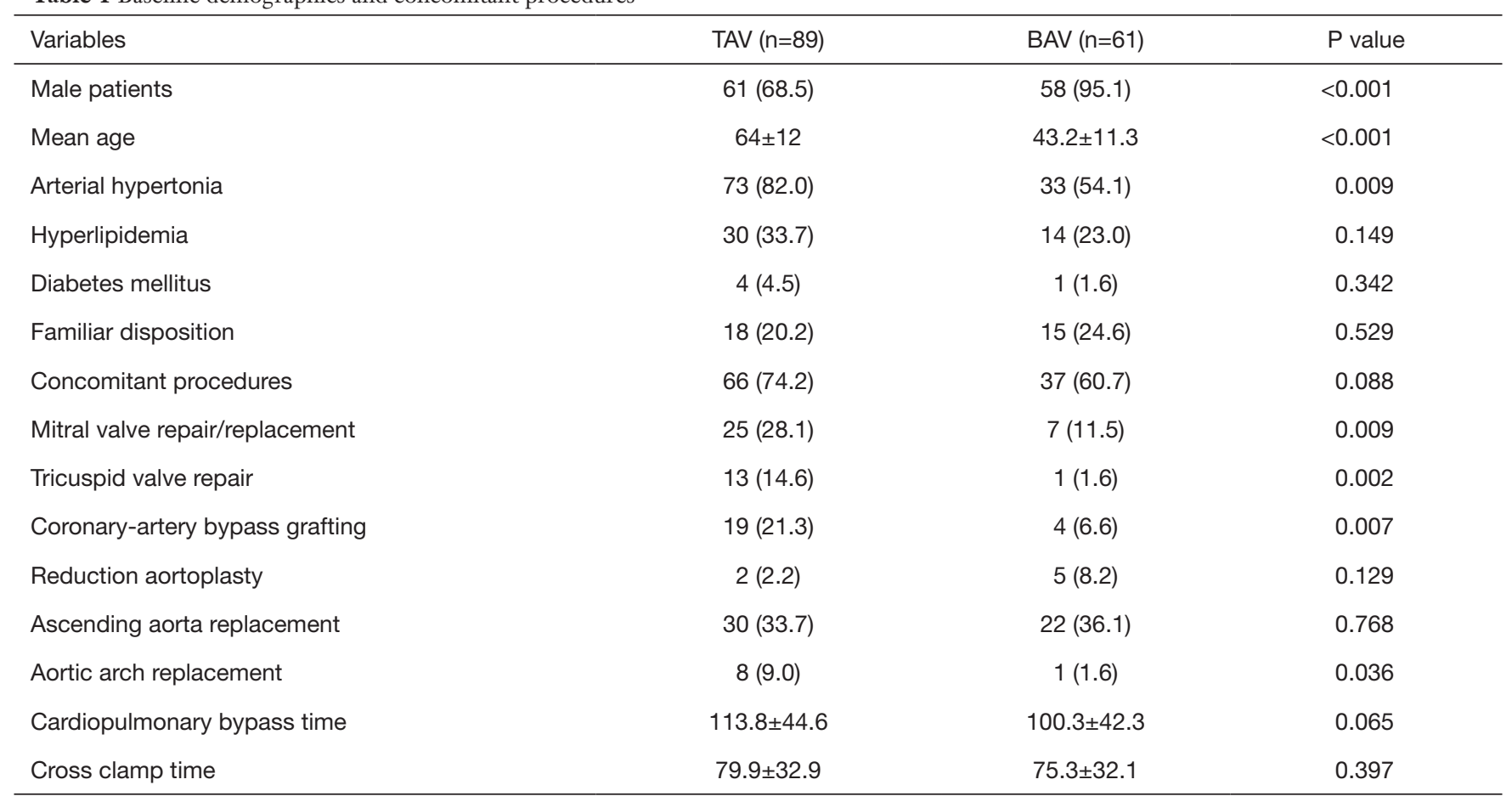

Data are shown as mean \pm SD or number (percentage). BAV, bicuspid aortic valve; TAV, tricuspid aortic valve.

(Table 2).

In $5(5.6 \%)$ of the patients with TAV and $3(4.9 \%)$ of those with BAV, redo procedures had to be performed during the same hospital stay, owing to recurrent AR in 7 patients $(4.7 \%)$ and aortic stenosis in 1 patient $(0.7 \%$, BAV group). Of these, 7 were treated with prosthetic valve replacement and 1 underwent re-reconstruction. During the initial hospital stay, 4 patients $(2.7 \%)$ died. During followup, reoperation had to be performed in 8 patients with TAV (9\%) and 8 with BAV (13.1\%). The cause of recurrent AR was cusp prolapse in 2 patients (1.3\%), annular dilatation in $3(2 \%)$, cusp tear in $3(2 \%)$, cusp restriction in $3(2 \%)$, patch degeneration in 3 cases (2\%), and acute dissection of the aortic root in $1(0.7 \%)$. One patient developed aortic stenosis after implantation of an autologous pericardial patch. The patch calcified and caused restrictive motion and stenosis.

Compared to preoperative data in patients with TAV, only LVEDD significantly changed at discharge and followup, while in patients with BAV, LVEDD, LVESD, P max, and $\mathrm{P}$ mean significantly changed. Intergroup comparison showed at discharge and follow-up significantly higher maximum $(\mathrm{P}<0.001, \mathrm{P}=0.003)$ and mean $(\mathrm{P}=0.001$ each $)$ pressure gradients in BAV. At discharge, the EOA was significantly larger after TAV repair $(\mathrm{P}=0.008)$, but not at follow-up $(\mathrm{P}=0.601)$. Detailed echocardiographic data can be found in Tables 2,3 and a graphic visualization of selected parameters in Figure 1A,B,C.

Survival in patients with TAV at 1 (93.1\%; CI: $87.8-$ 98.4\%), 5 (91.2\%; CI: $84.7-97.7 \%$ ), and 8 years $(88.4 \%$; CI: $80.2-96.6 \%)$ was significantly decreased compared to survival in patients with BAV (100\%, CI: $100-100 \%$; 96.2\%, CI: $88.8-100 \%$; and $96.2 \%$, CI: $88.8-100 \%$; $\mathrm{P}=0.033$, Figure $2 A)$. Freedom from reoperation at 1,5 , and 8 years was $91.9 \%$ (CI: 86.2-97.6\%), 82.5\% (CI: 73.791.3\%), and $82.5 \%$ (CI: 73.7-91.3\%) in patients with TAV and $88.3 \%$ (CI: $80.1-96.5 \%$ ), $77.8 \%$ (CI: $65.7-89.6 \%$ ), and $77.8 \%$ (CI: $65.7-89.6 \%$ ) in patients with BAV (Figure $2 B$ ). No significant differences were found in patients with TAV compared to those with $\mathrm{BAV}(\mathrm{P}=0.651)$.

According to our above-described classification, 17 patients $(11.3 \%)$ were allocated to patch implantation, 34 (22.7\%) to triangular resection, 48 (32\%) to cusp plication, and $39(26 \%)$ to isolated SCA (Figure 3A). Miscellaneous procedures were carried out in 12 patients $(8 \%)$. Freedom from reoperation was highest for patients who underwent 
Table 2 Echocardiographic parameters at baseline, discharge, and follow-up

\begin{tabular}{|c|c|c|c|}
\hline Parameter & Tricuspid valve $(n=89)$ & Bicuspid valve $(n=61)$ & BAV vs. TAV \\
\hline \multicolumn{4}{|l|}{ Preoperative } \\
\hline \multicolumn{4}{|l|}{ Aortic regurgitation } \\
\hline None & $2(2.2)$ & $1(1.6)$ & \\
\hline Mild & $21(23.6)$ & $11(18)$ & \\
\hline Severe & $33(37.1)$ & $38(62.3)$ & \\
\hline LVEF & $57.3 \pm 8.3$ & $57.8 \pm 5.6$ & 0.752 \\
\hline LVEDD & $58.1 \pm 9.4$ & $60.3 \pm 8.1$ & 0.169 \\
\hline LVESD & $38.6 \pm 9.4$ & $41.3 \pm 7.3$ & 0.161 \\
\hline Maximum gradient & $13.7 \pm 12.8$ & $15.4 \pm 7.1$ & 0.499 \\
\hline Mean gradient & $7.3 \pm 7.4$ & $8.5 \pm 4$ & 0.430 \\
\hline EOA & $2.7 \pm 0.6$ & $2.9 \pm 1.3$ & 0.593 \\
\hline \multicolumn{4}{|l|}{ Discharge } \\
\hline \multicolumn{4}{|l|}{ AR } \\
\hline None & $26(29.9)$ & $38(62.3)$ & \\
\hline Mild & $48(55.2)$ & $19(31.1)$ & \\
\hline Moderate & $11(12.6)$ & $1(1.6)$ & \\
\hline Aortic root & $35.9 \pm 5.5$ & $36.6 \pm 4.1$ & 0.568 \\
\hline Ascending aorta & $32.9 \pm 3.6$ & $32.6 \pm 4.5$ & 0.773 \\
\hline Maximum gradient & $16.2 \pm 7.3$ & $22.7 \pm 11$ & $<0.001$ \\
\hline Mean gradient & $8.5 \pm 3.9$ & $13.8 \pm 7.3$ & $<0.001$ \\
\hline EOA & $2.5 \pm 0.9$ & $1.9 \pm 0.7$ & 0.008 \\
\hline \multicolumn{4}{|l|}{ Follow-up } \\
\hline \multicolumn{4}{|l|}{ AR } \\
\hline None & $12(15.8)$ & $31(55.4)$ & \\
\hline Mild & $44(57.9)$ & $12(21.4)$ & \\
\hline Moderate & $18(20.2)$ & $4(7.1)$ & \\
\hline Severe & $2(2.6)$ & 9 (16.1) & \\
\hline LVEF & $57.5 \pm 9.8$ & $59.9 \pm 7.5$ & 0.142 \\
\hline
\end{tabular}

Table 2 (continued) 
Table 2 (continued)

\begin{tabular}{lccc}
\hline Parameter & Tricuspid valve $(\mathrm{n}=89)$ & Bicuspid valve $(\mathrm{n}=61)$ & BAV vs. TAV \\
\hline LVEDD & $54.2 \pm 7.4$ & $54.3 \pm 7.9$ & 0.982 \\
LVESD & $35.9 \pm 8.7$ & $36.7 \pm 8.4$ & 0.735 \\
Aortic root & $37.9 \pm 6.1$ & $37.9 \pm 5.9$ & 0.997 \\
Ascending aorta & $35.3 \pm 5.3$ & $34.5 \pm 4.5$ & 0.527 \\
Maximum gradient & $14.2 \pm 10.8$ & $22.1 \pm 10.2$ & 0.003 \\
Mean gradient & $6.9 \pm 3$ & $12.7 \pm 7.5$ & 0.001 \\
EOA & $2.3 \pm 0.8$ & $2.2 \pm 0.9$ & 0.610 \\
\hline
\end{tabular}

Data are shown as mean \pm SD or number (percentage). Aortic root, aortic root diameter (mm); AR, aortic regurgitation; Ascending aorta, diameter of the ascending aorta $(\mathrm{mm})$; EOA, effective orifice area $\left(\mathrm{cm}^{2}\right)$; LVEDD, left ventricular end-diastolic diameter (mm); LVEF, left ventricular ejection fraction (\%); LVESD, left ventricular end-systolic diameter (mm); P max, maximum gradient (mmHg); P mean, mean gradient $(\mathrm{mmHg})$.

Table 3 Comparison of selected echocardiographic parameters at baseline, discharge and follow- up for tricuspid valves and bicuspid valves

\begin{tabular}{|c|c|c|c|c|c|c|}
\hline Parameter & \multicolumn{3}{|c|}{ Tricuspid valves } & \multicolumn{3}{|c|}{ Bicuspid valves } \\
\hline LVEDD & $<0.001$ & 0.002 & 0.154 & $<0.001$ & 0.002 & 0.154 \\
\hline Ascending aorta & $<0.001$ & 0.001 & 0.07 & $<0.001$ & 0.001 & 0.161 \\
\hline Maximum gradient & 0.592 & 0.374 & 0.232 & 0.592 & 0.374 & 0.232 \\
\hline Mean gradient & 0.005 & 0.638 & $<0.001$ & 0.005 & 0.638 & $<0.001$ \\
\hline
\end{tabular}

Aortic root, aortic root diameter $(\mathrm{mm})$; Ascending aorta, diameter of the ascending aorta $(\mathrm{mm})$; EOA, effective orifice area (cm²); LVEDD, left ventricular end-diastolic diameter (mm); LVEF, left ventricular ejection fraction (\%); LVESD, left ventricular end-systolic diameter (mm).

isolated SCA (94.2\%; CI: 86.4-100\%), followed by triangular resection (87.9\%; CI: 72.6-100\%) and plication (72.2\%; CI: 55.1-89.3\%). Following patch repair, freedom from reoperation was significantly lower $(33.2 \% \pm 17.7 \%$, CI: $0-67.9 \%$; $\mathrm{P}=0.001$ ).

We further stratified the patients with TAV or BAV. Among those with TAV, 6 patients $(6.7 \%)$ were in the patch group, $3(3.4 \%)$ in the resection group, $35(39.3 \%)$ in the plication group, and $36(40.4 \%)$ in the SCA group. Nine patients $(10.1 \%)$ underwent repair techniques not included in this analysis. After 72 months, freedom from reoperation was highest in the triangular resection group $(100 \%$; CI:
$100-100 \%)$ and lowest in the patch repair group (66.7\%, CI: 29.1-100\%; Figure 3B). Among the patients with BAV, 11 patients $(18 \%)$ were in the patch repair group, 31 (50.8\%) in the resection group, $13(21.3 \%)$ in the plication group, and $3(4.9 \%)$ in the subcommissural annuloplasty group. Three patients $(4.9 \%)$ underwent repair types not included in this analysis. After 72 months, freedom from reoperation was highest in the isolated SCA group (100\%, CI: 100 $100 \%)$ and lowest in the patch repair group (20.7\%, CI: $0-55.8 \%$; Figure $3 C$ ). Due to small patient numbers in each subgroup, a statistical comparison between TAV and BAV was not feasible. 

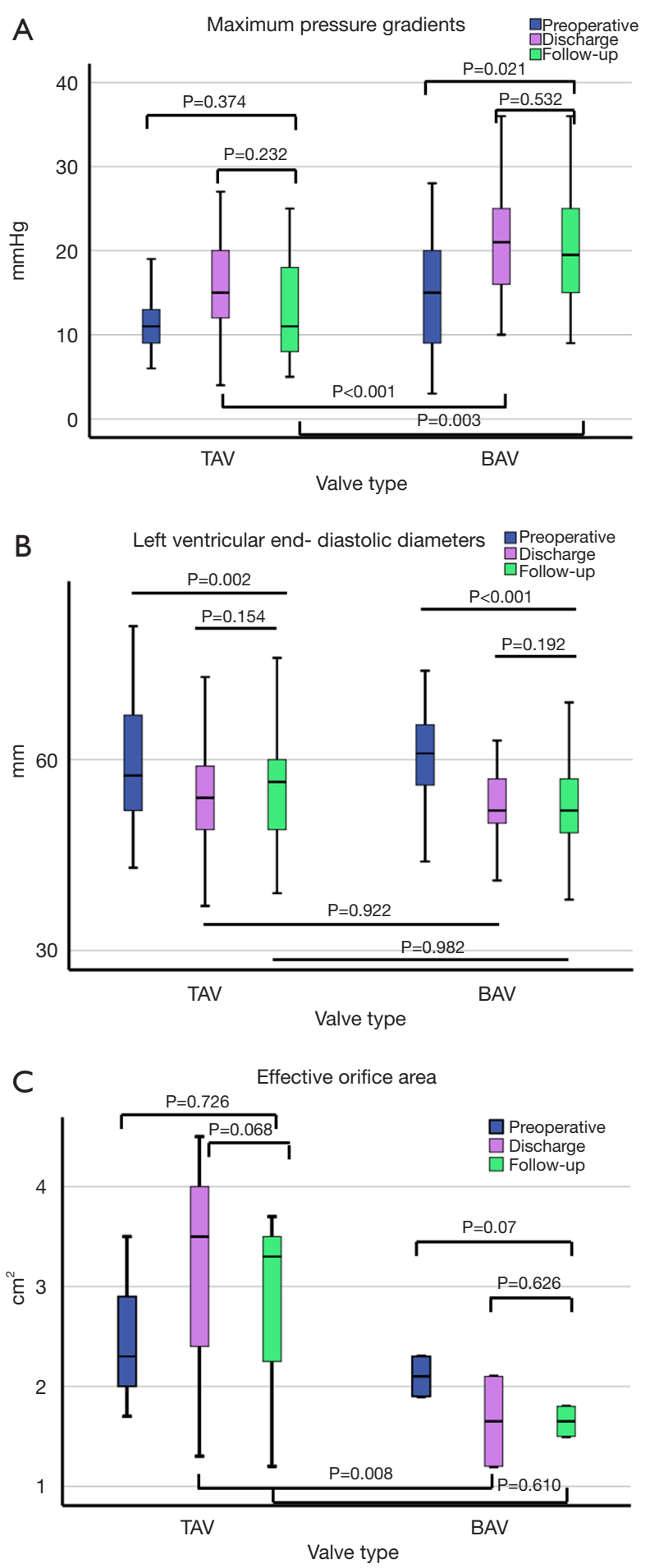

Figure 1 Boxplots of selected echocardiographic parameters preoperatively, at discharge and follow-up, stratified by valve types: (A) maximum pressure gradients ( $\mathrm{mmHg}$ ); (B) left-ventricular enddiastolic diameters $(\mathrm{mm})$; (C) effective orifice area $\left(\mathrm{cm}^{2}\right)$. BAV, bicuspid aortic valve; TAV, tricuspid aortic valve.

\section{Discussion}

Primary pathologies of the aortic cusps, including prolapse, calcification, and fenestrations, can lead to isolated AR (10) The feasibility of AV-repair in patients with either bi- or tricuspid aortic valves has previously been demonstrated $(1,11,12)$. In the present study, we sought to evaluate reoperation rates, recurrence of regurgitation, and survival in patients with either BAV or TAV after AV-repair without additional aortic root procedures, as in these patients reimplantation techniques alone are often effective (3).

In our series, 133 of the patients $(88.7 \%)$ underwent SCA. Reduction of the aortic annulus is important for long-term valvular competence (13-16), but recurrence of annular dilatation after SCA has been reported. The potential mechanism is the incomplete stabilization of the annulus due to non-circumferential stitches (16). For cases without significant dilatation of the aortic root, alternative techniques have been described. Schneider and colleagues reported the use of an external subannular suture for annuloplasty. According to the body surface area (BSA), the annulus is either reduced or merely stabilized to their proposed annulus diameter of $25 \mathrm{~mm}$ in patients with a BSA $\geq 2 \mathrm{~m}^{2}$ and $23 \mathrm{~mm}$ in patients with a BSA $<2 \mathrm{~m}^{2}(17)$. In $268 \mathrm{BAV}$-patients, freedom from reoperation improved after 5 years to $92.6 \%$, compared to $73.2 \%$ without suture annuloplasty. Six patients (3.7\%) had complications related to the subannular suture, such as ventricular septal defects and compromise of coronary arteries (15)

Lansac and colleagues introduced a ring to either reduce or stabilize the aortic annulus $(13,18)$. In their series of isolated $\mathrm{AV}$-repair cases, they report $97.5 \%$ freedom from reoperation, with $82.2 \%$ freedom from $A R \geq$ grade 3 and $57.3 \%$ freedom from $A R \geq$ grade 2 after 7 years. If the size of the sinotubular junction was $>35 \mathrm{~mm}$, a second ring in supracoronary position was added to increase coaptation in cases of central AR (19). A third approach is the HAARTring, which has been evaluated in our center. Based on mathematical analyses of CT angiograms, a specially designed ring for either TAV or BAV is implanted in a subvalvular position. Among TAV-patients, 7 (10.8\%) reportedly required reoperation within three years, and among BAV-patients, 2 out of $16(14,20)$.

In our study population, results after isolated SCA were excellent. Freedom from reoperation was $93.6 \%$ (CI: 85.2-100\%) in TAV-patients and 100\% (CI: 100-100\%) in BAV-patients. These results reflect the effectiveness of SCA to achieve sufficient treatment of pure annular 

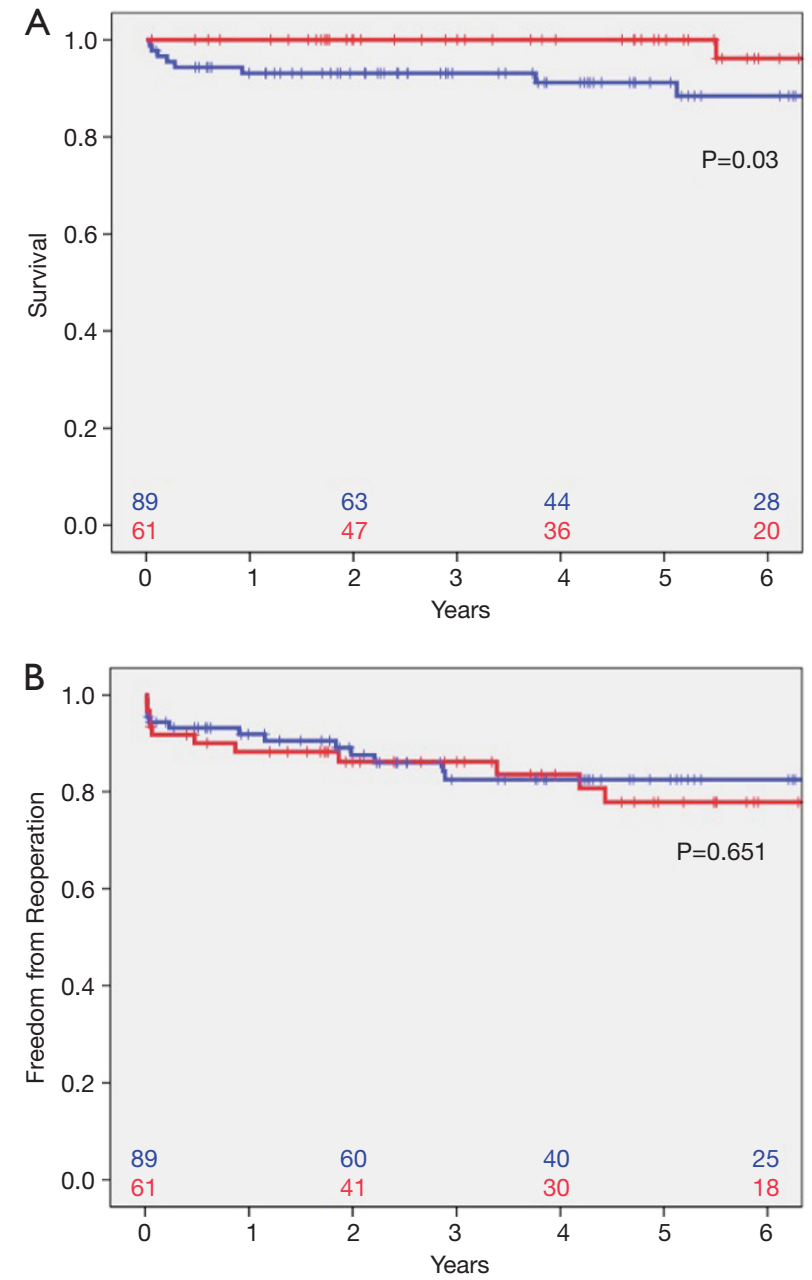

Figure 2 Kaplan-Meier curves. (A) Survival; (B) Freedom from reoperation. Blue: Tricuspid aortic valves. Red: Bicuspid aortic valves.

dilatation without additional pathologies of the cusps. Even in patients with more complex aortic valve pathologies, SCA is a fast and safe procedure that obviates the need for dissection of the aortic root. Therefore, we perform SCA in all patients undergoing $\mathrm{AV}$-repair without excessive annular dilatation for annulus stabilization. In patients presenting with ascending aortic aneurysms and central AR, one mechanism causing AR is the dilatation of the sinotubular junction. Although this pathomechanism can be addressed by supracoronary aortic replacement, additional SCA is recommended to stabilize the aortic annulus (21). In our cohort, supracoronary aortic replacement was performed in $35.6 \%$ of TAV and $44.3 \%$ of BAV.

The second most performed technique in our series was cusp plication (86 cases; $57.3 \%$ ). The surgical technique
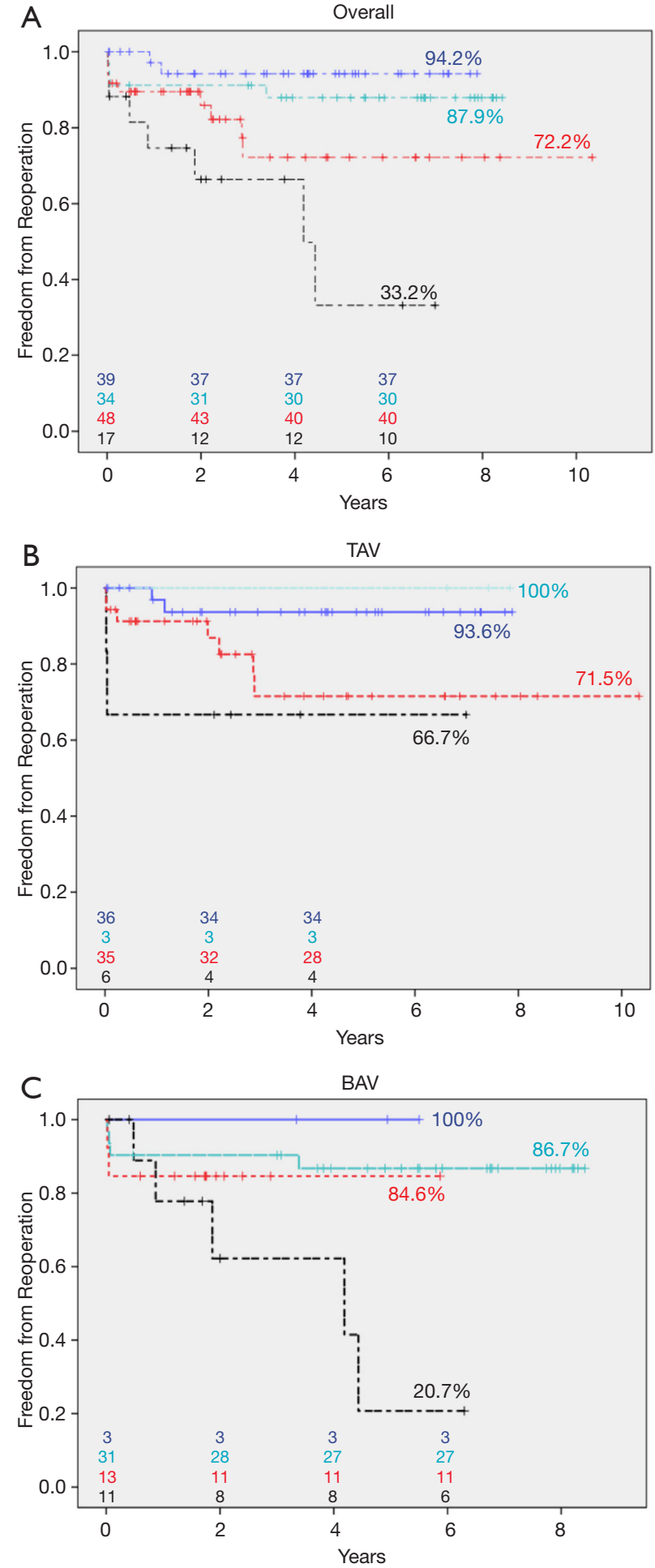

Figure 3 Results ordered by different techniques. (A) Overall results; (B) tricuspid aortic valves; (C) bicuspid valves. Blue: Subcommissural annuloplasty. Turquoise: Triangular resection. Red: Plication. Black: Patch implantation. Percentages are estimated values. BAV, bicuspid aortic valves. 
and favorable results are described elsewhere (22-24). In our series, freedom from reoperation was $71.5 \%$ (CI: $52.7-$ 90.3\%) for TAV and 84.6\% (CI: 65-100\%) for BAV. Cusp plication can be applied for limited cusp prolapse with tissue quality suitable for reconstruction $(25,26)$. We perform this technique by plicating the prolapsing central free margin, using the non-prolapsing cusps as a reference to achieve coaptation of all cusps. Studies showed the ability to predict the likelihood of AV-repair success by measurement of the effective height as a surrogate parameter for coaptation, as there is a correlation between the coaptation height and freedom from recurrent AR. Measured from the annular plane to the central free margin, an effective height of at least $8 \mathrm{~mm}$ should be the goal in every AV-repair $(27,28)$.

Triangular resection was applied in 43 patients (28.7\%) $(22,29)$. According to our internal classification, 34 patients $(22.7 \%)$ were treated with triangular resection. The remaining 9 patients underwent additional patch augmentation during AV-repair. Our results showed 100\% (CI: $100-100 \%)$ freedom from reoperation for TAV $(n=3)$ and $86.7 \%$ (CI: 74.6-98.9\%) for BAV (n=31). Applied mostly in patients with $\mathrm{BAV}$, this technique allows resection of prolapsing leaflet parts with poorer tissue quality, creating a sufficient level of coaptation. Excessive resection of tissue should be avoided, and careful re-adaptation is mandatory to avoid secondary suture dehiscence. In cases of severe cusp prolapse, this technique offers a safe and reproducible option to treat prolapse and ensure sufficient coaptation.

Patch augmentation of diseased cusps with autologous pericardium was used in 6 patients with TAV (6.7\%) and in 11 with BAV (18\%) with freedom from reoperation of $66.7 \%$ (CI: 29.1-100\%) and $20.7 \%$ (CI: 0-55.8\%), respectively. Use of patch material may lead to a suboptimal outcome after $\mathrm{AV}$ - repair $(11,26,30,31)$, as calcification and degradation of the material can occur with consecutive distortion of cusp symmetry. One could speculate that alteration of cusp mobility leads to increased mechanical stress and increased risk of repair failure. Mechanical properties of autologous pericardium, as well as those of commercially available pericardium, differ and are dependent on the time of fixation and orientation of the material (32).

AR causes volume overload of the left ventricle, inducing ventricular dilatation and further progression to end-stage heart failure. Increased LVEDD and LVESD represent this volume overload in echocardiographic examinations. Once valvular competence is reestablished, remodeling of the ventricle begins (33). In our study, we observed left ventricular remodeling after $\mathrm{AV}$-repair for TAV and BAV, shown by a significant reduction of LVEDD on followup echocardiography. Accordingly, the comparison of preoperative and follow-up LVEF showed no significant difference. This underlines the efficacy of AV-repair to restore normal physiological blood flow, thereby inducing remodeling of the ventricle.

In patients undergoing $A V$-repair is always the risk of overcorrection of cusp pathologies with reduction of cusp mobility, resulting in increased pressure gradients up to aortic stenosis. In our series, follow-up examinations revealed no significant changes of maximum and mean pressure gradients and EOA in TAV-patients. In contrast, in BAVpatients, pressure gradients were significantly increased. Although described before, the underlying mechanisms are not fully understood $(13,34)$. One can speculate that changes in leaflet geometry and mobility may be responsible for increased pressure gradients due to annulus diameter reduction, reduced leaflet mobility by triangular resection, or excessive plication or patch augmentation. Nevertheless, EOA was unchanged in these patients.

In the present study, overall survival was $93.3 \%$. BAVpatients had significantly better survival compared to patients with TAV, but they were significantly younger and had fewer concomitant procedures and emergency operations than those with TAV. Freedom from reoperation did not differ significantly between patients with TAV (85.4\%) and BAV (82\%); these results accord with those reported in current literature $(11,26,31)$. In contrast, replacement of diseased aortic valves with prostheses shows excellent results with regard to reoperation rates and freedom from survival. Glaser and colleagues report in a series of 4,545 patients undergoing either mechanical or biological valve replacement a 5 -year survival of $92 \%$ for mechanical and $89 \%$ for biological prostheses. In the same cohort, $2.2 \%$ of the patients with mechanical valves and $5.2 \%$ with biological valves had to undergo reoperation and nearly $10 \%$ of the patients receiving a mechanical valve suffered from a major bleeding event (35). Avoidance of oral anticoagulation is possible if AV-repair is performed or biological valves are used, but there is strong evidence that after biological valve replacement, younger patients' age is a risk factor for earlier structural valve deterioration, exposing patients to the risk of repeated reoperations (36).

Limitations of this study are the relatively small number of patients and the limited follow- up time. The advantage of this study is that the presented results are not biased by inclusion of patients undergoing root procedures. 
In conclusion, $\mathrm{AV}$-repair is a safe and feasible option in patients with AR and can achieve similar results in patients with TAV and BAV. The complexity of the repair technique predicts repair failure, with the worst outcomes in patients undergoing patch augmentation. In patients requiring multiple and complex repair techniques, i.e., patch implantation, prosthetic valve replacement should be considered.

\section{Acknowledgments}

Funding: None.

\section{Footnote}

Reporting Checklist: The authors have completed the STROBE reporting checklist. Available at http://dx.doi. org/10.21037/jtd-19-4193

Data Sharing Statement: available at available at http:// dx.doi.org/10.21037/jtd-19-4193

Conflicts of Interest: All authors have completed the ICMJE uniform disclosure form (available at http://dx.doi. org/10.21037/jtd-19-4193). MK serves as an unpaid editorial board member of Fournal of Thoracic Disease from Aug 2019 to Jul 2021. The other authors have no conflicts of interest to declare.

Ethical Statement: The authors are accountable for all aspects of the work in ensuring that questions related to the accuracy or integrity of any part of the work are appropriately investigated and resolved. The study was conducted in accordance with the Declaration of Helsinki (as revised in 2013). The local ethic committee of the medical faculty at the Technical University of Munich approved this study (524/19 S). Data were obtained from the hospital medical record system and personal data were secured before analysis. Informed consent was waived due to the nature of the study.

Open Access Statement: This is an Open Access article distributed in accordance with the Creative Commons Attribution-NonCommercial-NoDerivs 4.0 International License (CC BY-NC-ND 4.0), which permits the noncommercial replication and distribution of the article with the strict proviso that no changes or edits are made and the original work is properly cited (including links to both the formal publication through the relevant DOI and the license). See: https://creativecommons.org/licenses/by-nc-nd/4.0/.

\section{References}

1. Price J, De Kerchove L, Glineur D, et al. Risk of valverelated events after aortic valve repair. Ann Thorac Surg 2013;95:606-12; discussion 613.

2. Aicher D, Fries R, Rodionycheva S, et al. Aortic valve repair leads to a low incidence of valve-related complications. Eur J Cardiothorac Surg 2010;37:127-32.

3. Bavaria JE, Desai N, Szeto WY, et al. Valve-sparing root reimplantation and leaflet repair in a bicuspid aortic valve: Comparison with the 3-cusp David procedure. J Thorac Cardiovasc Surg 2015;149:S22-8.

4. Sareyyupoglu B, Suri RM, Schaff HV, et al. Survival and reoperation risk following bicuspid aortic valve-sparing root replacement. J Heart Valve Dis 2009;18:1-8.

5. Svensson LG, Al Kindi AH, Vivacqua A, et al. Long-term durability of bicuspid aortic valve repair. Ann Thorac Surg 2014;97:1539-47; discussion 1548.

6. Vohra HA, Whistance RN, De Kerchove L, et al. Valvepreserving surgery on the bicuspid aortic valve. Eur J Cardiothorac Surg 2013;43:888-98.

7. Badiu CC, Bleiziffer S, Eichinger WB, et al. Are bicuspid aortic valves a limitation for aortic valve repair? Eur J Cardiothorac Surg 2011;40:1097-104.

8. Zoghbi WA, Enriquez-Sarano M, Foster E, et al. Recommendations for evaluation of the severity of native valvular regurgitation with two-dimensional and Doppler echocardiography. J Am Soc Echocardiogr 2003;16:777-802.

9. Sievers HH, Schmidtke C. A classification system for the bicuspid aortic valve from 304 surgical specimens. J Thorac Cardiovasc Surg 2007;133:1226-33.

10. Langer F, Aicher D, Kissinger A, et al. Aortic valve repair using a differentiated surgical strategy. Circulation 2004;110:II67-73.

11. Aicher D, Holz A, Feldner S, et al. Quality of life after aortic valve surgery: replacement versus reconstruction. J Thorac Cardiovasc Surg 2011;142:e19-24.

12. Zeeshan A, Idrees JJ, Johnston DR, et al. Durability of Aortic Valve Cusp Repair With and Without Annular Support. Ann Thorac Surg 2018;105:739-48.

13. Lansac E, Di Centa I, Sleilaty G, et al. Long-term results of external aortic ring annuloplasty for aortic valve repair. Eur J Cardiothorac Surg 2016;50:350-60.

14. Mazzitelli D, Fischlein T, Rankin JS, et al. Geometric 
ring annuloplasty as an adjunct to aortic valve repair: clinical investigation of the HAART 300 device. Eur J Cardiothorac Surg 2016;49:987-93.

15. Schneider U, Hofmann C, Aicher D, et al. Suture Annuloplasty Significantly Improves the Durability of Bicuspid Aortic Valve Repair. Ann Thorac Surg 2017;103:504-10.

16. de Kerchove L, Mastrobuoni S, Boodhwani M, et al. The role of annular dimension and annuloplasty in tricuspid aortic valve repair. Eur J Cardiothorac Surg 2016;49:42837; discussion 437-8.

17. Schneider U, Aicher D, Miura Y, et al. Suture Annuloplasty in Aortic Valve Repair. Ann Thorac Surg 2016;101:783-5.

18. Lansac E, Di Centa I, Raoux F, et al. An expansible aortic ring for a physiological approach to conservative aortic valve surgery. J Thorac Cardiovasc Surg 2009;138:718-24.

19. Lansac E, Di Centa I, Raoux F, et al. A lesional classification to standardize surgical management of aortic insufficiency towards valve repair. Eur J Cardiothorac Surg 2008;33:872-8; discussion 878-80.

20. Mazzitelli D, Pfeiffer S, Rankin JS, et al. A Regulated Trial of Bicuspid Aortic Valve Repair Supported by Geometric Ring Annuloplasty. Ann Thorac Surg 2015;99:2010-6.

21. Boodhwani M, de Kerchove L, Glineur D, et al. Repairoriented classification of aortic insufficiency: impact on surgical techniques and clinical outcomes. J Thorac Cardiovasc Surg 2009;137:286-94.

22. Boodhwani M, El Khoury G. Aortic valve repair. J Thorac Cardiovasc Surg 2010;140:S20-2.

23. Boodhwani M, de Kerchove L, Glineur D, et al. A simple method for the quantification and correction of aortic cusp prolapse by means of free margin plication. J Thorac Cardiovasc Surg 2010;139:1075-7.

24. Aicher D, Langer F, Adam O, et al. Cusp repair in aortic valve reconstruction: does the technique affect stability? J Thorac Cardiovasc Surg 2007;134:1533-8; discussion 1538-9.

25. Settepani F, Cappai A, Raffa GM, et al. Cusp repair during aortic valve-sparing operation: technical aspects and impact on results. J Cardiovasc Med (Hagerstown) 2015;16:310-7.

26. Tanaka H, Takahashi H, Inoue $T$, et al. Which technique of cusp repair is durable in reimplantation procedure? Eur J Cardiothorac Surg 2017;52:112-7.

27. Bierbach BO, Aicher D, Issa OA, et al. Aortic root and cusp configuration determine aortic valve function. Eur J Cardiothorac Surg 2010;38:400-6.

28. Schäfers HJ, Bierbach B, Aicher D. A new approach to the assessment of aortic cusp geometry. J Thorac Cardiovasc Surg 2006;132:436-8.

29. Boodhwani M, El Khoury G. Aortic valve repair: indications and outcomes. Curr Cardiol Rep 2014;16:490.

30. Aicher D, Kunihara T, Abou Issa O, et al. Valve configuration determines long-term results after repair of the bicuspid aortic valve. Circulation 2011;123:178-85.

31. Ram E, Moshkovitz Y, Shinfeld A, et al. Pericardial Patch Augmentation Is Associated With a Higher Risk of Recurrent Aortic Insufficiency. Ann Thorac Surg 2018;106:1171-7.

32. Hofferberth SC, Baird CW, Hoganson DM, et al. Mechanical properties of autologous pericardium change with fixation time: implications for valve reconstruction. Semin Thorac Cardiovasc Surg 2019;31:852-4.

33. Leshnower BG, Guyton RA, McPherson L, et al. Improved left ventricular function and remodeling after the david v for significant aortic insufficiency. Ann Thorac Surg 2013;96:2090-4.

34. Ko H, Bavaria JE, Habertheuer A, et al. Functional Outcomes of Type I Bicuspid Aortic Valve Repair With Annular Stabilization: Subcommissural Annuloplasty Versus External Subannular Aortic Ring. Ann Thorac Surg 2019;107:68-75.

35. Glaser N, Jackson V, Holzmann MJ, et al. Aortic valve replacement with mechanical vs. biological prostheses in patients aged 50-69 years. Eur Heart J 2016;37:2658-67.

36. Ochi A, Cheng K, Zhao B, et al. Patient Risk Factors for Bioprosthetic Aortic Valve Degeneration: A Systematic Review and Meta-Analysis. Heart Lung Circ 2020;29:668-78.
Cite this article as: Prinzing A, Boehm J, Erlebach M, Sideris $\mathrm{K}$, Lange R, Krane M. Comparison of outcomes following isolated repair of tricuspid versus bicuspid aortic valves. J Thorac Dis 2020;12(7):3514-3523. doi: 10.21037/jtd-19-4193 